\title{
Omega-3 supplementation associated with nutritional advice improves oxidative stress and inflammation markers in chronic renal failure patients
}

\author{
A. Boukaddoum ${ }^{1}$, W. Taleb ${ }^{1}$, N. Bouzidi ${ }^{1}$, K. Mekki $^{1}$, A. Kaddous ${ }^{2}$ and M. Bouchenak ${ }^{1}$ \\ ${ }^{1}$ Laboratoire de Nutrition Clinique et Métabolique, Département de Biologie, Faculté des Sciences, Université d'Oran \\ Es-Sénia, Algérie and ${ }^{2}$ Service de Néphrologie, E.H.U d'Oran, Algérie
}

\begin{abstract}
Chronic inflammation is associated with the occurrence of cardiovascular events during chronic renal failure (CRF). Oxidative stress in CRF represents major components of inflammation and is exacerbated by dialysis. The aim of this study was to evaluate the effect of a balanced diet supplemented with omega-3 polyunsaturated fatty acids (PUFA) on markers of oxidative stress and inflammation in CRF patients.

Thirty CRF patients $(61 \pm 14$ years $)$ with hypertriglyceridaemia $(\mathrm{TG}>1.7 \mathrm{mmol} / \mathrm{l})$ and/or hypercholesterolaemia $(\mathrm{CT}>5 \mathrm{mmol} / \mathrm{l})$ received nutritional councils adapted to $\mathrm{CRF}$ (energy intake of $0.12 \mathrm{MJ} / \mathrm{kg} \mathrm{BW} / \mathrm{d}$, protein intake $0.8 \mathrm{~g} / \mathrm{kg} \mathrm{BW} / \mathrm{d}$, lipid intake $35 \%$ of total energy intake with $28 \%$ PUFA, $37 \%$ of monounsaturated fatty acid and $35 \%$ saturated fatty acids) and were randomised into two groups, 15 patients received a supplementation with omega-3 fish oil $2.1 \mathrm{~g} / \mathrm{d}$ during 90 days and 15 patients were used as controls. To evaluate the monitoring of recommendations, nutritional survey was carried out at baseline and 12 weeks. Blood samples were drawn after a $12 \mathrm{~h}$ overnight fasting, at the beginning (T0), 30 (T1), 60 (T2) and 90 days (T3) after initiating intervention. Serum lipid peroxidation was measured by thiobarbituric acid reactive substances (TBARS) analysis ${ }^{(1)}$. Oxidised proteins were estimated by carbonyls concentrations ${ }^{(2)}$. Superoxide dismutase (SOD) and glutathione peroxidase (GSH-Px) were determined by Cayman Chemical kits. Catalase (CAT) activity was measured according to Aebi ${ }^{(3)}$. Albumin and urate were determined by colorimetric methods. Total proteins were assessed according to Lowry et al. ${ }^{(4)}$. Haemoglobin, bilirubin and iron were analysed by colorimetric methods and C-reactive protein (CRP) was assessed by Omega Diagnostics Kit.

Results showed that in CRF group supplemented with omega-3, TBARS were lowered by $-25 \%$ at $\mathrm{T} 1(P<0.05)$ and $-54 \%$ at $\mathrm{T} 3$ $(P<0.001)$ compared to control group, and a progressive decrease was noted at T1 $(-30 \%)$, T2 $(-36 \%)$ and T3 $(-53 \%)$, compared to T0 $(P<0.001)$. There was no significant difference in carbonyls values in omega-3 group. SOD activity was increased in omega-3 group compared to control group at T1 $(+29 \% ; P<0.05)$, T2 $(+37 \% ; P<0.001)$ and T3 $(+32 \% ; P<0.001)$. Omega-3 enhanced GSH-Px by $51 \%$ at $\mathrm{T} 1(\mathrm{P}<0.001), 49 \%$ at $\mathrm{T} 2(\mathrm{P}<0.001)$ and $74 \%$ at T3 $(\mathrm{P}<0.001)$. GSH-Px activity was $1.7-, 1.98-$ and $2.07-$ fold higher at T1, T2 and T3, respectively compared to T0 $(\mathrm{P}<0.001)$. Increase in CAT activity was noted only at T2 $(36 \%)$ and T3 (41\%). Albumin, total proteins, iron values were similar in both the groups. Uric acid concentrations were elevated at T3 compared to T0 $(P<0.05)$. However, CRP, haemoglobin and bilirubin concentrations were lower respectively by 25,20 and $30 \%$ in omega-3 group at T3.
\end{abstract}

We conclude that in CRF patients, Omega-3 supplementation improves lipid peroxidation and enhances antioxidant enzymes activity, which leads to an attenuation of inflammation, therefore protection against cardiovascular complications occurrence.

1. Quintanilha AT, Packer L, Davies JM et al. (1982) Ann NY Acad Sci 393, 32-47.

2. Levine RL, Garland D, Oliver CN et al. (1990) Methods Enzymol. 186, 464-478.

3. Aebi H (1974) Catalase. In: Berg Meyer H (Ed.) 2nd edn. Verlag Chemie, Weinheim, Germany, pp. 673-684.

4. Lowry OH, Rosebrough NJ, Farr AL et al. (1951) J Biol Chem 193, 265-275. 